\section{Consultório na Rua em uma capital do Nordeste brasileiro: o olhar de pessoas em situação de vulnerabilidade social}

\author{
A Street Clinic in a state capital in Northeast Brazil \\ from the perspective of homeless people
}

\author{
Consultorio de Calle en una capital del Nordeste \\ brasileño: perspectiva de personas en situación \\ de vulnerabilidad social
}

Cíntia Priscila da Silva Ferreira 1

Célia Alves Rozendo 1

Givânya Bezerra de Melo 1

\begin{abstract}
Resumo
O objetivo deste estudo foi avaliar a estratégia do Consultório na Rua em Maceió, Alagoas, Brasil, com base na perspectiva de seus usuários. Pesquisa de abordagem qualitativa, cujo cenário foram os campos de atuação da estratégia Consultório na Rua em Maceió. Os sujeitos da pesquisa foram 18 pessoas em situação de rua atendidas pela estratégia, sendo dez homens e oito mulheres, com idades entre 20 e 40 anos. A coleta de dados se deu entre setembro de 2014 e fevereiro de 2015, sendo empregada a técnica de entrevista semiestruturada. Os dados foram analisados por meio da técnica de análise de conteúdo e apontaram duas categorias: a primeira, Consultório na Rua como ele é, revelou os nós críticos, desafios e potencialidades dessa estratégia; a segunda, Consultório na Rua: suporte social, afeto e perspectiva de mudança, para quem se encontra em situação de rua. Os resultados demonstraram que a estratégia é avaliada positivamente e que se constitui como suporte social não apenas em questões relativas à saúde-doença, mas também em aspectos da vida cotidiana.
\end{abstract}

Avaliação de Serviços de Saúde; Pessoas em Situação de Rua; Pesquisa Qualitativa

\author{
1 Universidade Federal de \\ Alagoas, Maceió, Brasil. \\ Correspondência \\ C. P. S. Ferreira \\ Escola de Farmácia e \\ Enfermagem, Universidade \\ Federal de Alagoas. \\ Av. Lourival Melo Mota s/n, \\ Campus A.C. Simões, Maceió, \\ AL 57072-970, Brasil. \\ cintiapriscila_19@hotmail.com
}




\section{Introdução}

O aumento do contingente da população em situação de rua é realidade em vários países 1,2,3. No Brasil, este fenômeno está presente principalmente nas grandes cidades. Os censos populacionais realizados pelo Instituto Brasileiro de Geografia e Estatística (IBGE) não dispõem de dados reais sobre essa população, uma vez que reconhecem somente os que habitam domicílios regulares ou coletivos 4 . Contudo, levantamentos nacionais trazem à tona questões relativas a essas pessoas: quem são, seu cotidiano, motivos que os levaram a viver nas ruas, dentre outras 5,6,7. A realidade desse grupo populacional aponta para pessoas vivendo em extrema vulnerabilidade social, cujas vidas são demarcadas por privações de direitos, rompimento de vínculos afetivos, violência, sofrimento e estigmas 8,9.

As especificidades e a complexidade dos fatores envolvidos no cotidiano das pessoas em situação de rua desafiam os vários setores e serviços da sociedade, dentre eles o Sistema Único de Saúde (SUS). Nesse sentido, o Ministério da Saúde vem apresentando iniciativas dirigidas à atenção a esse grupo, dentre elas o Plano Operativo para Implementação de Ações em Saúde da População em Situação de Rua 2012-2015, o Consultório de Rua e o Consultório na Rua 10,11,12.

Com base no Consultório de Rua, surgiu o Programa Saúde da Família Sem Domicílio, experiência levada a cabo em algumas cidades como Porto Alegre (Rio Grande do Sul), São Paulo e Belo Horizonte (Minas Gerais) 11,13. Por sua vez, a estratégia Consultório na Rua surgiu em 2012 a partir da convergência de diferentes modalidades e experiências, como: Redução de Danos, Programa Saúde da Família (PSF) sem domicílio e Consultório de Rua. Vinculado à Política Nacional de Atenção Básica, o Consultório na Rua incorpora práticas de prevenção de doenças e promoção da saúde, busca melhoria do acesso aos serviços de saúde e tentativa de proteção da qualidade de vida, pautando-se nos princípios do SUS 13 .

Todavia, não basta a criação e implementação de uma estratégia, sendo necessária, também, sua avaliação. Diante do exposto, o presente estudo pretende ser uma contribuição para, especialmente, apoiar a tomada de decisões no âmbito das políticas públicas dirigidas a esse grupo populacional e/ou à estratégia Consultório na Rua.

O Consultório na Rua ajusta-se à dinâmica local, construindo seu setting terapêutico com base no vínculo e no acolhimento à população em questão; portanto, a equipe deve conhecer as especificidades do grupo atendido e conside- rar as características do território, assim como seu contexto 14,15. Ademais, o Consultório na Rua constitui uma modalidade de atendimento aos diferentes problemas e necessidades de saúde da população em situação de rua 11. Sua efetivação se dá por meio da atuação das equipes de consultório na rua, as quais se responsabilizam pelo cuidado a essa população, procurando atuar numa abordagem integral à saúde 11 .

Observa-se, nessa parcela populacional, dificuldade de acesso ao trabalho, aos serviços da rede de saúde e de educação, além da exposição cotidiana à violência, entre outros. Entretanto, cada cidade tem características sociais, econômicas, políticas e culturais que a diferem das outras cidades, produzindo singularidades na população que vive em situação de rua em cada contexto. No caso da cidade do presente estudo, a realidade social é marcada por profundas desigualdades sociais e violência urbana. Acrescenta-se a isso quadro político conservador, pouco favorável a mudanças. No âmbito da saúde, o desafio consiste em superar indicadores desfavoráveis e melhorar os processos de gestão dos serviços de saúde e as relações intersetorias.

Em qualquer contexto, a avaliação deve constituir-se como um procedimento habitual e cotidiano na gestão de serviços de saúde, sendo parte integrante e necessária ao planejamento e indispensável ao processo de tomada de decisões 16 . Logo, ouvir os sujeitos a quem são dirigidas as ações e/ou políticas de saúde é fundamental para a avaliação. As percepções e entendimentos dos sujeitos e toda a complexidade envolvida não são medidas por meio de inquéritos ou expressas numericamente. De fato, a avaliação qualitativa presta-se ao aprofundamento do objeto avaliado e à incorporação da subjetividade presente no processo avaliativo, dando-se voz aos sujeitos que vivem a experiência concreta dos serviços ou programas de saúde 17.

Embora não descarte a inclusão de outros aspectos, a avaliação qualitativa "necessariamente inclui os atores envolvidos na produção das práticas, suas demandas subjetivas, valores, sentimentos e desejos" 18 (p. 150). Sendo assim, o objetivo deste estudo foi avaliar a estratégia do Consultório na Rua em Maceió, Alagoas, Brasil, valendo-se da perspectiva de seus usuários.

\section{Metodologia}

Esta pesquisa adotou a abordagem qualitativa, com enfoque na avaliação qualitativo-participativa. O processo de desvelamento da singularidade e do sentido presente no vivido dos usuários junto a determinados programas, tem na 
pesquisa qualitativa um profícuo caminho metodológico ${ }^{17}$. Esse enfoque visa a incorporar dimensões tradicionalmente excluídas na prática avaliativa, tais como alteridade, subjetividade $\mathrm{e}$ participação dos distintos sujeitos envolvidos no processo avaliado 19 .

Os cenários foram os campos de atuação do Consultório na Rua em Maceió. O município tem seis equipes de Consultório na Rua, o qual tem, desde 2009, um projeto chamado Fique de Boa. Em 2010, passou a atender essa população por meio da estratégia Consultório de Rua, vinculado ao programa de Saúde Mental do município. Em 2012, constituiu-se como Consultório na Rua, vinculando-se à atenção básica. Maceió não dispõe de inquéritos sobre pessoas em situação de rua, no entanto dados de junho de 2015, levantados durante o período da pesquisa, indicavam 1.340 pessoas cadastradas pela estratégia.

Participaram da pesquisa 18 indivíduos em situação de rua atendidos pelos profissionais do Consultório na Rua, sendo dez homens e oito mulheres com idades entre 20 e 40 anos; todos foram encontrados e contactados nos cenários de atuação das equipes. A escolha dos sujeitos não se deu por representatividade estatística, mas, sim, pela possibilidade de responder aos objetivos do estudo, contemplando todos os campos de atuação do Consultório na Rua. O número de participante foi delimitado pelo critério de saturação teórica, e os critérios de inclusão foram: ser maior de 18 anos, estar em situação de rua e já ter sido atendido pelo Consultório na Rua. Considerando-se a alta mobilidade das pessoas que vivem em situação de rua, optou-se por entrevistar sujeitos que mantinham alguma permanência nos cenários de atuação das equipes, processo facilitado pelos profissionais do Consultório na Rua.

Os dados foram coletados entre setembro de 2014 e fevereiro de 2015, mediante entrevistas realizadas por uma das autoras deste artigo. Uma vez que a entrevistadora não tinha qualquer vínculo com os participantes da pesquisa, foi necessária uma aproximação ao campo e aos sujeitos antes de iniciar a coleta dos dados. Tal aproximação se deu por um período de duas semanas, sob anuência e acompanhamento das seis equipes do Consultório na Rua.

As entrevistas foram conduzidas conforme o roteiro a seguir: (1) Como é sua vida nas ruas?; (2) O que você acha do Consultório na Rua?; (3) $O$ consultório atende suas necessidades na rua?; (4) Em que o Consultório na Rua é bom? Em que não ébom?; (5) Como você se sente com o atendimento dos profissionais do consultório?; (6) Como é sua relação com os profissionais?; (7) Já teve algum acontecimento ruim na relação com os profissio- nais?; (8) Você tem espaço para conversar com a equipe? Consegue expressar o que quer e o que precisa?; (9) Você é tratado de maneira única ou como se fosse qualquer pessoa que vive na rua?; (10) Você acha que esse atendimento contribuiu para melhorar sua vida na rua? Como?; e (11) Em que o Consultório na Rua precisa melhorar?

A escolha do espaço para realização da entrevista ficou a critério de cada entrevistado, podendo ser feita no veículo que transportava a equipe do consultório na rua ou em outro local que ele considerasse mais apropriado. Apenas uma entrevista foi realizada no veículo; as demais ocorreram nas ruas, a maioria em calçadas ou bancos. As entrevistas foram gravadas e transcritas na íntegra. Para garantir o anonimato dos participantes, as citações dos trechos extraídos das falas foram acompanhadas pela letra E, que representa "entrevistado", seguida de um número, do 1 ao 18, indicando a ordem da entrevista.

Para a análise dos dados, foi utilizada a técnica de análise de conteúdo categorial por temática, proposta por Bardin 20. Após a transcrição das entrevistas, foi realizada a leitura flutuante, acompanhada por sucessivas leituras e exploração minuciosa do material. Em seguida, ocorreu o tratamento dos resultados, gerando duas categorias.

O projeto foi aprovado pelo Comitê de Ética em Pesquisa da Universidade Federal de Alagoas, autorização CAAE no 33529114.0.0000.5013. Os entrevistados consentiram sua participação mediante assinatura do Termo de Consentimento Livre e Esclarecido (TCLE), sendo fornecidas informações sobre o objetivo da pesquisa, riscos, benefícios e direito à recusa. Este trabalho é resultante da dissertação de mestrado de uma das autoras, realizado no Programa de Pós-graduação em Enfermagem da Universidade Federal de Alagoas.

\section{Resultados e discussão}

A análise dos resultados apontou duas categorias: a primeira, Consultório na Rua como ele é, revela as potencialidades e os desafios dessa estratégia; a segunda, Consultório na Rua: suporte social, afeto e perspectiva de mudança, indica o que a estratégia representa para as pessoas em situação de rua por ela atendidas.

\section{O Consultório na Rua como ele é}

Nessa categoria, os participantes apontaram as potencialidades e os desafios do Consultório na Rua. Como potencialidades, destacaram-se o acolhimento e o vínculo, as ações desenvolvidas 
na rua e os "ensaios" de articulação intersetorial. Como desafios, foram indicados fatores relacionados à estrutura organizacional do Consultório na Rua e à articulação com a Rede de Atenção à Saúde (RAS).

$\mathrm{Na}$ análise das potencialidades, identificouse o uso de tecnologias leves de cuidado no cotidiano do trabalho do Consultório na Rua. Tais tecnologias se caracterizam pela utilização de ferramentas relacionais no cuidado em saúde que permitem o estabelecimento de relações de confiança e diálogo entre usuários e profissionais, além de favorecer a construção de vínculo, compromisso e responsabilização 21,22,23.

Vínculo e escuta são percebidos na relação entre usuários e equipes ao longo dos relatos. Observa-se, também, que as pessoas em situação de rua mostram gratidão pela existência do Consultório na Rua: "Se não fosse eles que levassem a gente ao médico, dar conselho, não existia ninguém, porque foi Deus que enviou vocês, pra vir salvar a gente dessa vida. Aí agradeço a cada um de vocês" (E3). "É como eles entendessem o que a gente necessita, e certas vezes a gente desabafa mesmo, é mais que consultório, é uma amizade" (E7).

Faz-se referência, ainda, à questão da singularidade: "Eles tratam a gente como se a gente fosse única, cada um é aquele sentimentozinho que eles plantam" (E7). Essas potencialidades devem ser pensadas em, pelo menos, duas perspectivas: por um lado, a existência de vínculo entre usuários e profissionais do Consultório na Rua; por outro, extrema gratidão e até certo endeusamento dos profissionais pelos usuários, o que pode sugerir falta de acesso aos recursos sociais, familiares e até uma existência não cidadã.

Observamos, assim, um contexto de marginalização, exclusão social e expropriação de direitos expresso maciçamente nesse grupo populacional, cuja trajetória não é marcada somente pela falta de moradia, mas por uma realidade muito mais complexa, evidenciada pela fragilidade dos vínculos sociais e familiares, pelo débil acesso às redes de atenção social e ao mundo do trabalho 9,24. Outro aspecto dessa fragilidade é a constante exposição a situações hostis, discriminatórias, violentas e perigosas. A gratidão pode ser mais uma expressão dessa fragilidade, na medida em que encontram nos profissionais uma das poucas possibilidades de acesso aos recursos sociais, ainda que isso deixe transparecer uma visão paternalista na relação estabelecida entre profissionais e usuários.

Outra potencialidade diz respeito às ações realizadas pelo Consultório na Rua: "Sempre traz medicamento pra quem precisa, traz a água pra hidratar, claro, e dá aquela força psicológica" (E1).
"Me ajuda em tudo, com remédio, com exame, conselho" (E2). "Foi uma boa vinda aqui pra Alagoas porque, quando não tinha ele, era pior com certeza, eles levam a gente pra fazer exame, negócio de HIV, mama, cuida muito da saúde daqueles que querem ir, mas não obriga, mas tenta, insiste" (E4). "Pra prevenir de doença, ajudar a gente, traz preservativo, água, eles conversam” (E7).

Esses achados condizem com um estudo realizado em 2013 com profissionais do Consultório na Rua da região metropolitana de Recife, cuja equipe desenvolvia ações de redução de danos e de atendimento básico de saúde, principalmente de enfermagem, como verificação de sinais vitais, pressão arterial e realização de curativos 25 .

Acolhimento e diálogo aparecem como elementos importantes na prática desses profissionais, presentes desde a implantação da primeira experiência em 2009 26. Essa é uma das habilidades mais importantes que os profissionais de saúde que atuam com pessoas em situação de rua devem exercitar e construir. É importante ressaltar que escuta e diálogo não são dons, podem ser aprendidos como parte das atitudes profissionais e das técnicas de comunicação que facilitam a conversa, a aceitação do outro, a empatia e o reconhecimento dos usuários como sujeitos que possuem direitos 27 .

Outra potencialidade se refere ao fato de as equipes de consultório na rua realizarem ações que vão além das questões de saúde-doença, buscando suprir as necessidades demandadas pelas pessoas atendidas. Essas ações se expressam especialmente pelo acesso aos serviços de saúde e de assistência social, como, por exemplo, encaminhamento de consultas na atenção básica, internamentos hospitalares e obtenção de documentos: "Já fizeram meu cartão do SUS. Chegou de um dia pro outro" (E1). "Ajudaram com o pré-natal, em consulta para os meninos, remédios, vacina em dia" (E5). "Fui internado em Arapiraca e passei um mês e dezenove dias, por causa do Consultório na Rua que me ajudou. Foi bom, eu voltei gordo e forte" (E8).

Essas ações indicam, por um lado, potencial para a intersetorialidade, ainda que se deem mais como "ensaios". Por outro lado, visibilizam a condição de extrema vulnerabilidade das pessoas em situação de rua. A compreensão dessa fragilidade requer a ampliação do olhar sobre o tema, deixando de vê-lo no plano puramente individual e passando a considerá-lo no plano das suscetibilidades socialmente configuradas. A atuação junto a grupos vulneráveis pressupõe abertura para ações intersetoriais e a formação de redes de atenção, promovendo a integração da saúde com outras áreas 28 . Essa integração, contudo, ainda é um desafio. 
No contexto da produção do cuidado, observamos o potencial da clínica ampliada, a qual propõe uma prática clínica mais complexa e longitudinal, colocando os sujeitos como foco das ações dos profissionais. Trata-se de uma prática baseada na negociação, no diálogo e no reconhecimento do desejo das pessoas, procurando distanciar-se das formas prescritivas de atuação. Pressupõe, ainda, a criação de espaços coletivos em que a produção do cuidado seja resultado da análise e da intervenção do trabalho em equipe 29 .

Como uma concepção epistemológica e organizacional, a clínica ampliada projeta-se para além das doenças ao inserir questões de saúde que envolvem a vida e a vulnerabilidade das pessoas. Assim, a atuação gira em torno da utilização dos recursos ao alcance da população e dos profissionais, privilegiando o trabalho intersetorial, procurando agregar diversas instâncias além das instituições de saúde 30 .

Quanto aos desafios, são apontadas questões relacionadas à estrutura organizacional do Consultório na Rua e à articulação com a RAS, a qual apresenta dificuldades de acesso do usuário quando não acompanhado de uma equipe de consultório na rua. Verifica-se preconceito dos profissionais de outros serviços da RAS em relação às pessoas em situação de rua.

Na estrutura organizacional do Consultório na Rua, ausência de sede e/ou espaço físico para atendimento dos usuários, ausência de veículo próprio e de recursos humanos insuficientes para a demanda foram referidos: "O que precisa melhorar é um espaço para eles exercer o trabalho deles aqui, porque tiraram eles daqui e ficou ruim pra gente, porque quando eles tinham um espaço aqui eles vinham direto e agora só vêm quando pode, porque eles não têm aqui só para atender e ajudar" (E7). "Se tivesse um local certo que o pessoal soubesse, não precisava nem eles andar, que eu mesmo procuraria que tivesse um ponto ou posto deles mesmo [...] pra mim seria melhor" (E12).

Uma usuária complementa que um local fixo beneficiaria tanto os trabalhadores do Consultório na Rua como os usuários, pois eles poderiam ir até a equipe. "Construir um espaço, mais conforto, onde eles possam estar aqui sempre ou a gente ir até a eles. Um espaço só pra eles eu acho, porque aqui tem muitos locais que dava sim pra fazer e não tá botando eles ali ou aqui, ou em cantos que não é apropriado pra eles" (E7).

Ressaltamos que cada equipe do Consultório na Rua deve estar vinculada a uma Unidade Básica de Saúde (UBS) no seu território de atuação. A existência de um espaço para essas equipes dentro dos equipamentos de saúde é preconizado, como contribuição à lógica de reversão da exclusão das pessoas em situação de rua. A garantia de um espaço em um serviço público permite ampliar a resolubilidade de algumas ações em saúde e, ainda, reconhecer que a pessoa que vive na rua é um cidadão de direitos, que pode e deve acessar qualquer serviço de saúde 31 . Nesse sentido, a equipe do Consultório na Rua, além de garantir um espaço físico nesses serviços, deve também legitimar o acesso das pessoas em situação de rua aos recursos disponíveis no sistema.

No entanto, no munícipio estudado, ainda existem entraves na gestão que dificultam a vinculação efetiva das equipes às unidades de saúde de referência. Apenas duas das seis equipes possuíam, no período do estudo, um espaço físico no interior das unidades; as demais funcionam em locais provisórios. Essa situação dificulta a vinculação e fidelização dos usuários do Consultório na Rua aos serviços e o acesso à equipe quando necessitarem.

Outro desafio apontado foi o transporte inadequado das equipes, o qual não é de exclusividade para as atividades do Consultório na Rua. Em face desse problema, geralmente ocorrem atrasos, o que ocasiona demora na chegada ao campo, diminuindo, assim, o tempo dispensado aos usuários. Os depoimentos a seguir apontam a carência de veículos a serviço do Consultório na Rua: "Queria que melhorasse os veículos, porque às vezes precisa ir pra um canto e não pode, porque o veículo tá ocupado" (E5). "Se tivesse mais veículo e apoio mais de alguém, porque só eles ainda tá muito pouco. É muita coisa, às vezes vêm no carro deles, que nem já aconteceu de vir, pra trazer o remédio da pessoa, aí é um problema não da parte deles, devia ter mais veículo, era melhor pra deslocar" (E12).

Além da necessidade de mais veículos, há indicação da necessidade de mais profissionais para atender o contingente de usuários: "É meio mundo de coisa e às vezes não pode vir porque está ocupado" (E12). "O prefeito devia dar condição para trabalhar melhor, dar mais produto pra eles, não só camisinha; mais profissional, mais pessoas para trabalhar e ajudar" (E15). "Acho que falta uns psicólogos pra sentar com a gente, conversar a parte pra saber o que o pessoal da rua tá passando" (E17).

Além das questões relativas à estrutura organizacional do Consultório na Rua, foram apontados desafios referentes à articulação com a RAS, os quais englobam dificuldades de acesso de pessoas em situação de rua sem a companhia dos profissionais do Consultório na Rua, burocratização e preconceito por parte dos profissionais de outros serviços. 
Os usuários conseguem perceber que o trabalho das equipes de consultórios na rua possibilita acesso aos serviços de saúde, apontando que, sem a atuação das equipes, é quase impossível ser atendido, principalmente porque os profissionais de saúde de alguns serviços da RAS não conseguem enxergá-los como pessoas que têm direitos, incluindo o direito à saúde, como se observa na seguinte fala: "Antes eu tinha dificuldade de ir pro posto, dificuldade de pegar remédio, de fazer exame e hoje eu não tenho" (E5). "A ajuda deles é boa demais, somente a ajuda deles, porque, se vai pro posto, não tem consulta, se não for eles na frente, não tem consulta" (E6).

Esses depoimentos caminham na direção de que os profissionais dos serviços de saúde da rede de atenção básica e hospitalar apresentam preconceito em relação a esses usuários e parecem até rejeitá-los e/ou ser indiferentes a eles, como aponta a seguinte declaração: “(...) porque antes a gente chegava lá pra se consultar ou alguma coisa, o povo já olhava feio, de cara feia, e hoje não, quando a gente vai com eles, a pessoa nem olha praticamente" (E5).

Chama a atenção, no depoimento E5, o fato de a invisibilidade ser tomada como algo positivo. Antes, sem a presença das equipes de consultório na rua, segundo esse usuário, os profissionais o olhavam e o tratavam de modo hostil. A partir do momento em que passou a ir ao serviço acompanhado por um elemento das equipes de consultório na rua, não mais era hostilizado, sequer era visto, percebido como pessoa. Pode-se supor que os profissionais da rede não estavam atendendo o usuário e sim o profissional da equipes de consultório na rua. O que é pior? A hostilidade evidente ou a indiferença escancarada?

Ambas são reveladoras da discriminação sofrida pelas pessoas em situação de rua. Ambas são demonstração do contexto de exclusão social em que essa população vive e remetem à perpetuação de ideias ao longo da construção da sociedade brasileira, causando uma repercussão devastadora nos excluídos 9 . Esses processos de exclusão têm origem em contextos diversos - social, econômico e político 32 .

Em consonância com esses achados, outra pesquisa 33 realizada com equipes do Consultório na Rua também afirma que existem desafios para o cuidado com as pessoas em situação de rua. Esses desafios constituem barreiras que dificultam, inibem ou até mesmo inviabilizam o acesso da pessoa nessa condição à rede de saúde e à rede intersetorial. A barreira social foi citada como uma das principais causas, a qual envolve estigma e reforça a invisibilidade desses indivíduos.

Nesse sentido, é necessário entender que, a partir da alteridade, do olhar do outro e para o outro, podemos olhar e perceber a nós mesmos. O estigma e a discriminação representam o avesso do reconhecimento da alteridade, é a negação da tolerância, do respeito pelas diferenças 34 . Assim, seria oportuno interrogar sobre os critérios e as razões presentes nas escolhas feitas pelas políticas públicas, que igualmente contribuem para a construção da imagem estereotipada de grupos marginalizados e de seus problemas 24

A insuficiente articulação com a RAS é um dos nós críticos a ser trabalhado. A burocratização dos serviços de saúde, a dificuldade de acesso motivado pelo preconceito e os problemas de articulação com a rede de atenção ainda são uma constante, embora os depoimentos demostrem melhoria no acesso aos serviços.

Consultório na Rua: suporte social, afeto e perspectiva de mudança para quem se encontra em situação de rua

Esta categoria apresenta o que o Consultório na Rua representa para as pessoas atendidas por essa estratégia. Para elas, trata-se de suporte social e apoio emocional, afeto e perspectiva de mudança de vida.

Suporte social e apoio emocional são tecnologias leves de cuidado demonstradas nos depoimentos: "A sensação é como se fosse uma família, porque trata a gente como se fosse um filho, não tem idade pra eles" (E4). "Eles ajudam bastante, conversam, são amigos, não são nem consultório. É uma amizade que eles criam com a gente, são carinhosos, o que podem ajudar que a gente necessita nem perguntam, a gente que já conhece que tem aquela intimidade, já chega neles" (E7).

$\mathrm{O}$ respeito e a resposta às necessidades singulares dos usuários podem ser observados em diversas situações: "É como eles entendessem o que a gente necessita, e certas vezes a gente desabafa mesmo, então é mais que um consultório, é uma amizade que a gente criou aqui na rua" (E7). Um relato de um dos entrevistados denota a sensibilidade da equipe ao realizar uma festa de aniversário que marcou a vida dele: "Até meu aniversário eles já fizeram. Eu tinha dito o dia do meu aniversário, aí passou vários tempos. Quando eu cheguei um dia aqui, estava mesa, bolo, doce, meio mundo de gente, eu chorei" (E1). "Ela veio, teve todo carinho, cuidou dele. Não aconteceu nesse consultório não, mas vi em outros lugares que trata você de uma forma diferente, vai lá só exercer a profissão, já eles vêm como seus amigos" (E7).

Os depoimentos sugerem que o cuidado nesse contexto da rua vai além de qualquer definição conceitual. Respeito à autonomia dessas pessoas e defesa de sua integridade dependem da existência de uma relação pertinente, permeada pela 
comunicação eficaz e afetiva. Tal comunicação envolve abandonar o tom paternalista 35 .

Porém, em um contexto de tamanha vulnerabilidade, será que a autonomia desses usuários é considerada, respeitada e salvaguardada? Até que ponto nós, como profissionais de saúde, estamos atuando numa perspectiva de resgate e/ ou de fortalecimento da cidadania? Até que ponto contribuímos para a perpetuação de uma ação política paternalista?

Esses questionamentos, contudo, também devem ser relativizados, tendo em vista as condições concretas e do contexto social e político em que se dá a atuação desses profissionais. Os usuários, por sua vez, na condição de extrema vulnerabilidade, são gratos por qualquer ação que seja feita a seu favor, desconhecendo que seus direitos, incluindo o direito à saúde, são usurpados. São gratos porque encontram no Consultório na Rua um ponto de apoio, talvez o único espaço que os conecta à sociedade, que os faz se sentirem cidadãos.

Dessa forma, alguns apontam que o Consultório na Rua trouxe mudança ou melhoria em suas vidas. Esse avanço tem relação com ações voltadas para promoção da vida, redução de danos sociais e melhoria das condições de saúde, por meio da atuação comprometida do Consultório na Rua, que é baseada na construção de vínculo e diálogo. No caso daqueles que usam drogas, há relatos de que conseguiram diminuir o uso como resultado da atuação dos profissionais do Consultório na Rua.

A mudança de vida também se relaciona à possibilidade de resgate de papéis familiares e reinserção familiar ou social: “Às vezes você está desesperançado, sem rumo, a doença que nem eu estava, não tinha condições de nada, eles chegaram devagarinho, fui ouvindo, os conselhos que eles dão. Eles trazem o remédio, mas não obriga você tomar, você tem que tomar; se não tomar, a pessoa mesmo se prejudica. É uma companhia que você sabe que tem" (E12). "Melhorou um bocado viu, porque diminui mais a droga" (E14). "Me afastei do mercado, botei a cabeça pra pensar. Estou cuidando do meu filho. O Consultório na Rua não pode deixar de andar na rua, porque eles são tudo que a pessoa tem na rua" (E4). "Com as nossas famílias já conversaram. Jáaconselharam pra voltar pra casa" (E15). "Com certeza, a minha vida e de muitos que vão pelos conselhos do consultório na rua melhoraram muito, se não fosse o Consultório na Rua, tinha existido mais doença, mais mortes. Dá água pra hidratar, preservativo pra se prevenir, não usa se não quiser; mas eles deixam" (E4). "Em tudo, na minha saúde, mudou 100\%, aprendi a me prevenir, aprendi a não compartilhar o cachimbo pra não pegar tuberculose" (E7).
Depreende-se desses depoimentos, portanto, que a atuação das equipes de Consultório na Rua faz diferença na vida das pessoas por elas atendidas. Os depoimentos indicam que, nessa atuação, estão presentes sensibilidade, afeto, apoio às demandas mais imediatas no campo biológico e psicológico, assim como, tentativa de reinserção social e familiar. Diálogo e acolhimento são elementos que parecem estar constantemente presentes nessa atuação.

A reinserção familiar e/ou social de uma pessoa em situação de rua, muitas vezes, é difícil, pois há perda do vínculo com a família, além do preconceito social e familiar, aumentando sua vulnerabilidade social. Em adição ao estigma social existente, a pessoa em situação de rua vive privações alimentares, financeiras, afetivas, além da exposição à violência constante 25.

Esse olhar sensível também dá lugar à escuta dos usuários como sujeitos, que falam de um espaço e experiência concretos, o que implica ouvir e considerar suas sugestões para melhorar o trabalho do Consultório na Rua. Nesse sentido, alguns deles apontam que os profissionais deveriam estar mais presentes e retomar algumas atividades lúdicas que faziam com a comunidade: "Eu queria que voltasse o projeto que eles tinham com as crianças de fazer brincadeira, de artesanato e pintura" (E5). "Tem que vir mais aqui, a gente não pode se acabar não. Acho que a galera tem outras localidades, é muito usuário, mas a gente precisa de mais atenção" (E1). "Ajuda [o Consultório na Rua] em tudo, em companheirismo, em colega, em conversar, em dar conselho, em trabalhar psicologicamente e fisicamente. Tipo quando eles fazem aquela aula de batuque" (E17).

Ao propor mudanças, o usuário torna-se sujeito ativo e participativo. É perceptível que eles têm uma visão ampliada sobre suas necessidades, apontando mudanças que consideram necessárias para melhorar a qualidade do Consultório na Rua para ambos: equipe e usuários.

Nessa direção também devem se encaminhar os processos avaliativos em saúde, de modo a romper com a lógica de que a avaliação de serviços deve ser usada somente para diminuir gastos na esfera pública ou para controlar aqueles que fazem parte do sistema avaliado. Assim, faz-se necessária a participação de trabalhadores e usuários nos processos avaliativos de programas e políticas de saúde. Tal participação implica experimentar modos de avaliação que produzam possibilidades de repensar a realidade, de ampliar a democratização dos processos pela escuta de diversos pontos de vista e sujeitos, de articular a necessidade do resultado com a atenção aos processos subjetivos e simbólicos 36 . 


\section{Considerações finais}

Os resultados deste estudo demonstraram que a estratégia Consultório na Rua é avaliada positivamente pelos usuários. Apoio social, afeto e oportunidade para mudar de vida são apontados pelos participantes da pesquisa. Eles destacaram, ainda, melhoria no acesso aos serviços de saúde, compromisso da equipe e relação de respeito estabelecida entre equipe e usuários. Nós críticos e desafios também foram indicados, dentre eles a inadequação da estrutura organizacional, o preconceito e a estigmatização das pessoas em situação de rua por alguns profissionais de serviços da RAS.

Ressaltamos a necessidade de engajamento da gestão e dos profissionais de saúde que estão em diversos espaços da RAS, considerando que a atenção às pessoas em situação de rua não é responsabilidade exclusiva dos profissionais que atuam no Consultório na Rua. Um desafio importante é o enfrentamento do preconceito em relação às pessoas que vivem em situação de rua.
Outro desafio diz respeito à adequação da rede de atenção social e de saúde para o atendimento apropriado a essa população, com foco no incremento das relações intersetoriais. O Consultório na Rua exerce um papel fundamental mas sozinho não é capaz de assumir as diversas demandas apresentadas pelos usuários, muitas além da capacidade resolutiva dos profissionais e da estratégia, visto que vários problemas têm origem na questão econômica e social.

Sendo assim, há de se pensar estrategicamente numa ação política junto a esses usuários, para que eles compreendam e, como sujeitos e cidadãos que são, enfrentem os desafios e assumam a luta por seus direitos. Há de se pensar também, em estratégias de sensibilização e de preparo dos profissionais das redes de atenção social e de saúde, para acolher e atender essa população direcionando-lhes o respeito, competência e dignidade com que devem ser tratados. A condição de viver na rua deve ser um fator de inclusão, já que essa mesma condição é o reflexo de extrema vulnerabilidade e de exclusão social.

\section{Colaboradores}

C. P. S. Ferreira, C. A. Rozendo e G. B. Melo contribuíram na concepção do projeto; análise e interpretação dos dados; redação do artigo; revisão crítica do conteúdo e aprovação final da versão a ser publicada.

\section{Referências}

1. Moura YG, Sanchez ZM, Opaleye ES, Neiva-Silva L, Koller SH, Noto AR. Drug use among street children and adolescents: what helps? Cad Saúde Pública 2012; 28:1371-80.

2. U. S. Conference of Mayors. Hunger and homelessness survey: a status report on hunger and homelessness in America's cities. Washington DC: City Policy Associates; 2014.

3. Rae BE, Rees S. The perceptions of homeless people regarding their healthcare needs and experiences of receiving health care. J Adv Nurs 2015: 71:2096-107.

4. Farias DCS, Rodrigues ILA, Nogueira LMV, Marinho IMC. Saberes sobre saúde entre pessoas vivendo em situação de rua. Psicol Saber Soc 2014; 3:70-82.

5. Meta Instituto de Pesquisa de Opinião. Pesquisa nacional sobre a população em situação de rua Brasília: Ministério do Desenvolvimento Social e Combate à Fome; 2008. 
6. Ministério do Desenvolvimento Social e Combate à Fome. Relatório do I Encontro Nacional sobre População em Situação de Rua. Brasília: Ministério do Desenvolvimento Social e Combate à Fome; 2006.

7. Governo Federal. Política Nacional para Inclusão Social da População em Situação de Rua para consulta pública. http://www.cidadeviva.org/ anjosdanoite/wp-content/uploads/2010/12/poli tica-nacional-para-inclusao-social-da-populacaoem-situacao-de-rua-para-consulta-publica.pdf (acessado em 26/Fev/2015).

8. Aguiar MM, Iriart JAB. Significados e práticas de saúde e doença entre a população em situação de rua em Salvador, Bahia, Brasil. Cad Saúde Pública 2012; 28:115-24.

9. Carneiro de Alcantara S, Pereira de Abreu D, Araujo Farias A. Pessoas em situação de rua: das trajetórias de exclusão social aos processos emancipatórios de formação de consciência, identidade e sentimento de pertença. Rev Colomb Psicol 2015; 24:129-43.

10. Ministério da Saúde. Plano operativo para implementação de ações em saúde da população em situação de rua 2012-2015. Brasília: Ministério da Saúde; 2012.

11. Ministério da Saúde. Manual sobre o cuidado à saúde junto a população em situação de rua. Brasília: Ministério da Saúde; 2012.

12. Carneiro Junior N, Jesus $\mathrm{CH}$, Crevelim MA. A Estratégia Saúde da Família para a equidade de acesso dirigida à população em situação de rua em grandes centros urbanos. Saúde Soc 2010; 19:709-16.

13. Londero MFP, Ceccim RB, Bilibio LFS. Consultório de/na rua: desafio para um cuidado em verso na saúde. Interface Comun Saúde Educ 2014; 18: 251-60.

14. Nery Filho A, Valério ALR, Monteiro LF. Guia do projeto consultório de rua. Brasília: Secretaria $\mathrm{Na}$ cional de Políticas sobre Drogas/Salvador: Centro de Estudos e Terapia do Abuso de Drogas; 2011.

15. Ministério da Saúde. Material de trabalho para a II Oficina Nacional de Consultórios de Rua do SUS. Brasília: Ministério da Saúde; 2010.

16. Tanaka OY, Melo C. Reflexões sobre a avaliação em serviços de saúde e a adoção das abordagens qualitativa e quantitativa. In: Bosi MLM, Mercado FJ, organizadores. Pesquisa qualitativa de serviços de saúde. 2a Ed. Petrópolis: Editora Vozes; 2007. p. 121-37.

17. Uchimura KY, Bosi MLM. Qualidade e subjetividade na avaliação de programas e serviços de saúde. Cad Saúde Pública 2002; 18:1561-9.

18. Bosi MLM, Uchimura KY. Avaliação da qualidade ou avaliação qualitativa do cuidado em saúde? Rev Saúde Pública 2007; 41:150-3.

19. Bosi MLM, Mercado-Martínez FJ. Modelos avaliativos e reforma sanitária brasileira: enfoque qualitativo-participativo. Rev Saúde Pública 2010; 44:566-70.

20. Bardin L. Análise de conteúdo. Lisboa: Edições 70; 2009.
21. Merhy EE, Franco TB. Por uma composição técnica do trabalho centrada no campo relacional e nas tecnologias leves. Saúde Debate 2003; 27:316-23.

22. Merhy EE. Em busca do tempo perdido: a micropolítica do trabalho vivo em saúde. In: Merhy EE, Onocko RT, organizadores. Agir em saúde: um desafio para o público. São Paulo: Editora Hucitec; 1997. p. 71-112.

23. Campos GWS. A mediação entre conhecimento e práticas sociais: a racionalidade da tecnologia leve, da práxis e da arte. Ciênc Saúde Coletiva 2011; 16:3033-40.

24. Castel R. A discriminação negativa: cidadãos ou autóctones? 2a Ed. Petrópolis: Editora Vozes; 2011.

25. Souza VCA, Pereira AR, Gontijo DT. A experiência no serviço de Consultório de Rua na perspectiva dos profissionais: contribuições para atenção ao usuário de álcool e outras drogas. Cad Ter Ocup UFSCar (Impr.) 2014; 22 Suppl Especial:S37-47.

26. Jorge JS, Corradi-Webster CM. Consultório de Rua: contribuições e desafios de uma prática em construção. Saúde Transform Soc 2012; 3:39-48.

27. Barros RS, Botazzo C. Subjetividade e clínica na atenção básica: narrativas, histórias de vida e realidade social. Ciênc Saúde Coletiva 2011; 16 : 4337-48.

28. Gama CAP, Campos RTO, Ferrer AL. Saúde mental e vulnerabilidade social: a direção do tratamento. Rev Latinoam Psicopatol Fundam 2014; 17:69-84.

29. Campos GWS, Figueiredo MD, Pereira Júnior N, Castro CP. A aplicação da metodologia Paideia no apoio institucional, no apoio matricial e na clínica ampliada. Interface Comun Saúde Educ 2014; 18 Suppl 2:S983-95.

30. Prates MML, Garcia VG, Moreno DMFC. Equipe de apoio e a construção coletiva do trabalho em saúde mental junto à Estratégia de Saúde da Família: espaço de discussão e de cuidado. Saúde Soc 2013; 22:642-52.

31. Lopes LE, organizador. Caderno de atividades: curso atenção integral à saúde de pessoas em situação de rua com ênfase nas equipes de consultórios na rua. Rio de Janeiro: Educação à Distância, Escola Nacional de Saúde Pública Sergio Arouca, Fundação Oswaldo Cruz; 2014.

32. Fernandez JCA. Determinantes culturais da saúde: uma abordagem para a promoção de equidade. Saúde Soc 2014; 23:167-79.

33. Silva FP, Frazão IS, Linhares FMP. Práticas de saúde das equipes dos Consultórios de Rua. Cad Saúde Pública 2014; 30:805-14.

34. Godoi AAM, Garrafa V. Leitura bioética do princípio de não discriminação e não estigmatização. Saúde Soc 2014; 23:157-66.

35. Villafranca RC, Guilhem D, Pérez KB. Medical paternalism. Rev Médica Electrón 2013; 35:144-52.

36. Campos RO, Furtado JO. Desafios da avaliação de programas e serviços de saúde. Campinas: Editora Unicamp; 2011. (Coleção Saúde, Cultura e Sociedade). 


\section{Abstract}

The objective of this study was to evaluate the Street Clinic strategy in Maceió, Alagoas State, Brazil, from the perspective of its users. This was a qualitative study in coverage areas of the Street Clinic in Maceió. Research subjects were 18 homeless individuals assisted by the clinic (10 men and 8 women), ranging from 20 to 40 years of age. Data were collected from Septem ber 2014 to February 2015 using a semi-structured interview. Content analysis was applied to the data and identified two categories: the first, the Street Clinic as such, revealed the strategy's critical points, challenges, and potentialities; the second showed the Street Clinic as social support, affect, and hope for change for the homeless. The strategy was rated positively by users, providing social support on health problems and other daily issues.

Health Services Evaluation; Homeless Persons; Qualitative Research

\section{Resumen}

El objetivo de este estudio fue evaluar la estrategia del Consultorio de Calle en Maceió, Alagoas, Brasil, desde la perspectiva de sus usuarios. Se trata de un estudio de enfoque cualitativo, cuyo escenario fueron las áreas de actuación de la estrategia Consultorio de Calle. Los sujetos de la investigación fueron 18 personas sin hogar, atendidas por la estrategia, siendo 10 hombres y 8 mujeres con edades entre 20 y 40 años. Los datos fueron recogidos entre septiembre de 2014 a febrero de 2015, mediante una técnica de entrevista semiestructurada. Los datos analizados mediante la técnica de análisis de contenido, apuntaron dos categorías: la primera, cómo es el Consultorio de calle, nos reveló los nudos críticos, desafios y potencialidades de esta estrategia; la segunda, Consultorio de Calle: apoyo social, afecto y perspectiva de cambio para quien no tiene hogar. Los resultados demostraron que la estrategia es evaluada positivamente y que la misma se constituye como apoyo social, no sólo en cuestiones relativas a salud-enfermedad, sino también en aspectos de la vida cotidiana.

Evaluación de Servicios de Salud; Personas sin Hogar; Investigación Cualitativa
Recebido em 04/Mai/2015

Versão final apresentada em 10/Out/2015 Aprovado em 18/Fev/2016 